signs were cutaneous ( 4 cases), articular (3 cases), renal (2 cases) and hematological in 1 case. The clinical picture was very polymorphic. Neurological involvement was found in 3 cases, whereas serous effusion was noted in 2 cases. One patient developed a macrophage activation syndrome. One patient required hemodialysis sessions. ne patient presented stage D pancreatitis. One patient had associated chronic septic granulomatous disease. Immunologically, all patients had elevated anti-nuclear $\mathrm{Ab}$ antibodies, 3 had native anti-DNA Ab, and two patients had anti-Sm positive Ab. Therapeutic options were: corticosteroids + Endoxan $^{\circledR}$ (4 cases), corticosteroids and plaquenil ${ }^{\circledR}$ (1 case) and plaquenil ${ }^{\circledR}+\operatorname{aspirin}^{\circledR}$ (1 case). Two patients died and a favorable outcome was noted in four other patients.

Conclusion SLE is a rare autoimmune disease in children. The clinico-biological picture is polymorphous with the possible involvement of multiple organs. The prognosis is conditioned by the renal damage.

\section{P619 REVIEW OF EPIDEMIOLOGY AND MANAGEMENT OF CHILDREN WITH PERIORBITAL AND ORBITAL CELLULITIS}

${ }^{1}$ Amruta Fulmali*, ${ }^{2}$ Dhani Bux. ${ }^{1}$ North Devon District Hospital, Barnstaple, UK; ${ }^{2}$ University Hospital Waterford, Waterford, Ireland

\subsection{6/archdischild-2019-epa.950}

Aim To study epidemiology and management of Periorbital and orbital cellulitis in children admitted in University Hospital Waterford, Ireland.

Methods The medical records of children $\leq 16$ years old and hospitalised from $01 / 01 / 2007$ to $31 / 12 / 2017$, at the University of Hospital Waterford with discharge code ICD-10-AM indicating diagnosis of acute inflammation of orbit were reviewed. Results Total 33 cases were included in this study.

\begin{tabular}{|c|c|c|}
\hline & $\begin{array}{l}\text { Orbital cellulitis } \\
\text { (Total } 9 \text { cases) }\end{array}$ & $\begin{array}{c}\text { Periorbital cellulitis } \\
\text { (Total } 24 \text { cases) }\end{array}$ \\
\hline Mean Age & 7 years & 7.8 years \\
\hline Male: Female ratio & 3.5 & 2.57 \\
\hline Eye swelling & 9 & 24 \\
\hline Headache & 0 & 3 \\
\hline Sepsis & 0 & 1 \\
\hline Vomiting & 0 & 0 \\
\hline Total cases who had FBC done & $9 / 9$ & $23 / 24$ \\
\hline$\uparrow W B C$ & 6 & 8 \\
\hline$\downarrow W B C$ & 0 & 2 \\
\hline Total cases who had CRP done & $5 / 9$ & $14 / 24$ \\
\hline$\uparrow C R P$ & 5 & 12 \\
\hline Total cases where blood culture was sent & 8 & 17 \\
\hline Blood Culture +ve & 0 & 1 (Coagulase Neg staph) \\
\hline Total Cases where CT was done & 9 & 11 \\
\hline Abnormal CT Scan & 9 & 7 \\
\hline Ophthalmological Examination & 9 & 23 \\
\hline ENT consultation & 8 & 13 \\
\hline Paediatric/Medicine Consultation & 7 & 23 \\
\hline Surgical drainage & 9 & 0 \\
\hline Local Antibiotic guideline followed & 3 & 1 \\
\hline Mean Duration of stay inpatient & 10.5 & 5 \\
\hline
\end{tabular}

Conclusion Literature says periorbital and orbital cellulitis typically affects a child under 5, but our main population was between 5-16 years with mean age of 7.8 years. Periorbital cellulitis occurs as a complication of sinusitis. All 9 children with orbital cellulitis had radiological evidence of sinusitis and 7 (29\%) out of 24 children with periorbital cellulitis had radiological evidence of sinusitis. So, $>70 \%$ children with periorbital cellulitis had source of infection other than sinusitis. Total of 9 children had Subperiosteal abscess which required drainage.

Discussion Epidemiology of Periorbital infections in Paediatric Population in that particular area was slightly different compared to the literature. Fortunately all children had good outcome after the appropriate treatment.

\section{P620 DISSEMINATED BARTONELLA HENSELAE INFECTION- CASE REPORT}

Diana Andreea Ciortea*. 'Carol Davila' University of Medicine and Pharmacy Bucharest, Bucharest, Romania

\subsection{6/archdischild-2019-epa.951}

Cat scratch disease is caused by Bartonella henselae- a fastidious gram-negative bacillus, and it has in most cases a self-limited evolution. However, it represents a challenge for diagnostic and treatment in immunosuppressed patients or in atypical and disseminated forms. We present the case of a 5year-old immunocompetent child, who was admitted into the hospital for fever and left peri-auricular adenopathy. After 7 days of antibiotic treatment with beta-lactams, the fever was persistent, and diffuse abdominal pain was associated. An abdominal-CT scan examination was performed, which showed hypo-attenuated focal lesions in the splenic and hepatic parenchyma, with subsequent micro-calcifications. Thus, the patient was diagnosed with disseminated Bartonella henselae infection, and secondary hepatic and splenic micro-abscesses, based on the combination of the epidemiological, clinical, imaging and serological criteria. The clinical evolution was favorable after 6 weeks of antibiotic treatment with a macrolide (azithromycin) associated for 2 weeks with an aminoglycoside (gentamycin).

\section{P621 HYDATIDOSIS IN INFANTS: WHAT NOT TO BE MISSED}

Lamia Gargouri, Imen El aoud, Fatma Hammemi, Chiraz Regaieg*, Faiza Safi, Abdellatif gargouri, Zeineb Mnif, Mounir Ben Jemaa, Makram Koubaa, Abdelmajid Mahfoudh. Hédi Chaker, Sfax, Tunisia

\subsection{6/archdischild-2019-epa.952}

Hydatidosis remains a major health problem in our country. In infants, pulmonary localization is more frequent while in adults the liver is the most affected site. It has many clinical and radiological features that may delay the diagnosis.

The aim of our study is to delineate some of the important characteristics of this affection in the pediatric population and to remind the atypical localization.

We lead a retrospective study over 29 years in the pediatric department of patients under the age of 18 years old. 23 patients were enrolled. We counted 18 males and 5 